\title{
Effects of Caring Children with Leukemia on their Mothers` Psychosocial Status
}

\author{
Adraa H. Shawq ${ }^{1}$, Khitam M. AL-Mousawi ${ }^{2}$, Zaid W. Ajil ${ }^{3}$ \\ ${ }^{1}$ Lecturer, ${ }^{2}$ Assistant Professor, ${ }^{3}$ Lecturer, Pediatric Nursing Department, College of Nursing, University of \\ Baghdad, Iraq
}

\begin{abstract}
Study aim: to assess the influence of care burden for children with leukemia on their mothers` psychosocial status.

Methodology: A Descriptive study, conducted at two pediatric hospitals in Baghdad city. A purposive sample of (60) mothers was participated in the study after obtaining their consent form. The instrument of the study was used to assess mothers` psychosocial status in addition to their sociodemographic characteristics. The data was processed and statistically analysed by SPSS program version 23 .
\end{abstract}

Result: the result of the study showed mothers have (81\%) in self esteem, (77\%) in psychosocial distress, $(80 \%)$ for social interaction, and $(76 \%)$ for social isolation. There were association between mothers psychosocial status and their age, educational level, and occupation.

Conclusion: the result of the study concluded that mothers of leukemic children have generally accepted level of psychosocial status except they isolated themselves.

Key words: psychosocial status, Children, Leukemia, effects

\section{Introduction}

Childhood cancer is a widely public health problem because of its negative influence on family and society. Leukemia is most common types of childhood cancers under 15 years of age, which represents $25 \%$ of all cancer in children. Like other terminal illness, it may cause several physical and mental problems for caregivers. Parents of leukemic children might experience various levels of anxiety and disappointment especially during initial stages of the diagnosis of their children ${ }^{(1,2 \text {, and }}$ 3); Mothers of children with cancer have participated in some educational programs that focused exclusively on improving child's health outcomes with less attention toward the needs of the caregivers. However, most mothers of leukemic children have psychosocial needs, which to be better if addressed in order to improve their general health status and provide best care for their children at home ${ }^{(4)}$. As reported in several studies that mothers of children with chronic diseases may suffer from different negative psychosocial consequences ${ }^{(5)}$.
Parents of children with leukemia challenged many effects of the disease and its burden. In addition to the cost of additional health care services with a long term follow up. In addition, theses concerns require more action on the part of parents in order to identify children's social and academic needs ${ }^{(1,6)}$. Park, et al (2016) conducted a study that showed psychosocial status depressive symptoms and worse quality of life in parents of children with advanced cancer ${ }^{(7)}$.

\section{Methods and Materials}

Research design: A descriptive study conducted at oncology units in pediatric hospitals; data was collected from November 1st 2018 to May 8th 2019.

Setting: The study was carried out at two pediatric teaching hospitals: child central pediatric teaching hospital and welfare pediatric teaching hospital in Baghdad city.

Instrument of the study and procedure: The 
questionnaire was developed on the basic of are view of the literature and the opus groups of parents. The questionnaire format was consisting of two parts : the first part is demographic data related to the mother, and the second part is related to the psychosocial effect of hospitalization on mother of children withleukemia in oncology units. The researchers using question that reflect mother behaviors (assessment to psycho and social characteristic ) that observed by parent. The answers were scored 1,2,3,4, and 5 (never, rarely very , sometimes , most of the time, every time) respectively. Validity of the instrument was coducted after experts reviewed and content validity was established. Furthermore, changes were made in questionnaire items according to the recommendation and notes of experts. The reliability of instrument was $\mathrm{r}=0.83$ at the level $(\mathrm{p} \leq$ $0.05)$ which was statistically acceptable.

\section{Statistical Analysis}

SPSS programme version 23 was used, frequency, percentage, and mean used in data analysis.

\section{Results}

$41 \%$ of mother their ages are between (35-44), $25 \%$ graduated for secondary school and $66 \%$ of mother their housewife according to their child demography data $42 \%$ of children have age between (10-12) years, $42 \%$ children 3-5 years age of onset disease, $60 \%$ of child male and $50 \%$ child first order in family.

Table 1. Mothers`psychosocial dimensions

\begin{tabular}{|l|l|l|l|}
\hline List & $\begin{array}{l}\text { Psychosocial } \\
\text { dimensions }\end{array}$ & Mean & Percent \\
\hline 1 & Self-esteem & 4.08 & $81 \%$ \\
\hline 2 & $\begin{array}{l}\text { Psychological } \\
\text { distress }\end{array}$ & 3.85 & $77 \%$ \\
\hline 3 & Social interaction & 4.01 & $80 \%$ \\
\hline 4 & Social isolation & 3.84 & $76 \%$ \\
\hline Total & & 3.94 & $78 \%$ \\
\hline
\end{tabular}

This table shows the mother response to psychosocial dimension and there is a High level in self esteem dimension and mean 4.08 Social interactions at mean 4.01, psychological distress at mean 3.85 , and social isolation at mean 3.84 respectively.

\section{Discussion}

The results of the present study showed that $41 \%$ of mother their ages are between (35-44), 25\%graduated for secondary school and $66 \%$ of mother their housewife according to their child demography data $42 \%$ of children have age between (10-12) years, $42 \%$ children 3-5 years age of onset disease, $60 \%$ of child male and $50 \%$ child first order in family. This result supported by the study conducted by Mahmoud and Elaziz (2015) it showed that the majority of caregivers' age is between (25-40) years old. Also, they found that most of caregivers were mother half of than are housewife. However, the study result supported that mothers of children with leukemia are more worthy to take care of their sick children than other family member ${ }^{(6)}$. Also, the study result shows that there is a high level of psychological and social stress among mothers of leukemia children when they response to psychological stress scale. This result consistent with the result of the study conducted by Creswell, Wisk, Litzelman, Allchin, and Witt (2014) that showed caring of children with advanced cancers was associated with increased to the diagnosis with relevant depressive symptoms in parents ${ }^{(7)}$. The findings of this study supported that mothers of children with cancer have high a high level of psychological and social stress. Many studies suggested that there are significant difference in the levels of stress, depressive, and anxiety among parents of children with cancer ${ }^{(8,9)}$. Parents' psychosocial status would affect by their children health conditions and the procedures of treatment of leukemia in the pediatric hospitals. Also, psychosocial status includes depressive symptoms like level of sadness, anxious, feeling of hopelessness, decreased energy, feeling of guilty, restlessness, and insomnia ${ }^{(9)}$. In addition, psychosocial status of mothers concerns their children with leukemia has a critical impact on their children's health status and other family members. However, parents of children with cancer need additional psychosocial interventions that would provide the necessary support during treatment periods (10). 
The present findings showed that mothers of children with leukemia have a high level in their self-esteem dimension during provide care for their children in the oncology units. Steiner, Shlonsky, and Joubert (2017) found that parents of children with end-stage cancer need additional psychosocial interventions services in order to increase child-parent communication and their coping skills to promote parental psychosocial wellbeing ${ }^{(11)}$.

The study result showed that there is an association relationship between mothers' psychosocial level and their demographic characteristics; correlation was significant at the level of 0.05 . This result consistent with the result of a study conducted by Bemis et al., 2015 that reported most socio demographic variables for mothers of children with cancers were positively correlated with all level of stress and depressive symptoms ${ }^{(17) .}$

\section{Conclusion}

The level of psychosocial status of mothers of children with leukemia showed acceptance and they have a high level of stress also all caregivers have stress of at different. However, there is an association between mothers' psychosocial level and their demographic characteristic such as mother age, educational level and occupational status.

\section{Recommendation}

Based on the study results, the study recommended:

1- Social institutions should provide psychosocial interventional programs for parents of children with leukemia to reduce the stress in the family and intervention programs to provide the information about coping strategies to help the families deal with the problem.

2- Activating the role of psychiatric nurses and social worker in pediatric hospitals in order to help families of children with leukemia to decrease the level of stress during their attendance to the hospital.

Conflict of Interest: The researchers report no conflict of interest.

Funding: This study did not receive any funding from any agency.

Ethical Clearance: A permission to conduct this study was obtained from the ethical committee in the college of nursing at University of Baghdad.

\section{References}

1. Demirtepe D, Bozo O. Predicting depressive symptoms among the mothers of children with leukaemia: A caregiver stress model perspective. Psychology \& Health. 2011; 26(5): 585-599.

2. Kholasehzadeh G, Shiryazdi S, Neamatzadeh H. Depression Levels among Mothers of Children with Leukemia. Iranian Journal of Pediatric Hematology And Oncolog. 2014; 4(3): 109-113.

3. Sabry Y, Zaki N, Elbahaey W. Assessing the coping strategies in a sample of mothers of Egyptian children with leukemia \& lymphoma. Arab Journal of Psychiatry. 2016; 27(1): 20-30.

4. Herba C, Tremblay R, Boivin, M. Maternal depressive symptoms and children's emotional problems: Can early child care help children of depressed mothers? JAMA Psychiatry. 2013; 70(8), 830-838.

5. Brooks J, Beil H, Beeber L. Maternal depressive symptoms and healthcare expenditures for publicly insured children with chronic health conditions. Maternal and Child Health Journal. 2015; 19(4): 790-797.

6. Mahmoud S, Elaziz N. Effect of PsychoEducational Training Program for Parent's Having Child with Leukemia on Their Experience and Psychological Wellbeing. Journal of Education and Practice. 2015; 6(12): 13-29.

7. Creswell P, Wisk L, Litzelman, K. Parental depressive symptoms and childhood cancer: the importance of financial difficulties. Supportive Care in Cancer. 2014; 22(2): 503-511.

8. Park E, Deal A, Check D. Parenting concerns, quality of life, and psychological distress in patients with advanced cancer. Psycho-Oncology. 2016; 25(8): 942-948.

9. Vernon L, Eyles D, Hulbert C. Infancy and pediatric cancer: an exploratory study of parent psychological distress. Psycho-Oncology. 2017; 26(3): 361-368.

10. Inhestern L, Haller A, Wlodarczyk O, Bergelt C. Psychosocial Interventions for Families with Parental Cancer and Barriers and Facilitators to Implementation and Use - A Systematic 
Review. PLoS ONE. 2016; 11(6): 1-20.

11. Steiner V, Shlonsky A, Joubert L. Psychosocial Interventions for Parents with Incurable End-Stage Cancer: A Rapid Evidence Assessment. Australian Psychologist. 2017; 52(5): 381-391.
12. Bemis H, Yarboi J, Gerhardt C. Childhood Cancer in Context: Sociodemographic Factors, Stress, and Psychological Distress Among Mothers and Children. Journal of Pediatric Psychology. 2015; 40(8): 733-743. 